\title{
CONSIDERAÇõES SôBRE AMOSTRAGEM DE PEIXES MARINHOS (II)
}

(Recebido em 8/5/61)

\author{
H. Nomura*
}

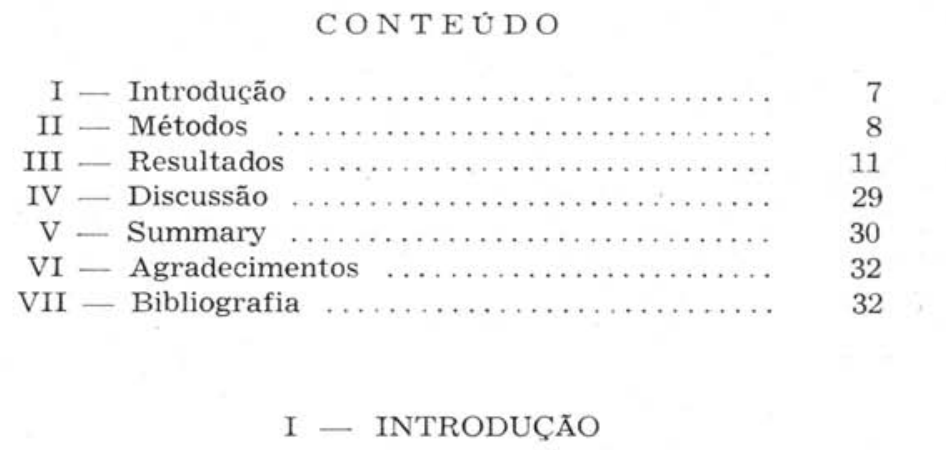

Um dos problemas mais importantes da investigação pesqueira consiste na obtenção de uma estimativa da distribuição de comprimentos dos peixes capturados e desembarcados.

Cada barco foi considerado como unidade de amostragem. Assim, tornou-se necessário saber como obter uma amostra, de tal modo que ela apresentasse uma avaliação exata da distribuição de comprimentos dos peixes desembarcados. Esta é a finalidade do presente trabalho, que se refere à amostragem da pescada-foguete - Macrodon ancylodon (Bloch, 1801) Jordan, Evermann \& Clark, 1930 - capturada pelas parelhas nipônicas que operam na região meridional do País e cujo desembarque se processa na cidade de Santos, Estado de São Paulo.

* Instituto Oceanográfico da Universidade de São Paulo. Membro do Grupo de Pesquisas sôbre a Pesca Maritima (G.P.P.M.).

Publ. n० 159 do Inst. Ocean. da USP.

Contr. n* 10 do G.P.P.M. 
Uma das considerações foi a verificação da variação que porventura existisse entre lances efetuados numa viagem. Essa variação pode ocorrer entre lances, numa viagem ou entre as viagens, devido à área na qual é realizado o lance. Para se estimar a fidedignidade da distribuição de comprimentos dos peixes desembarcados pelos barcos como sendo representativa da população capturada numa dada viagem, considerou-se interessante mostrar essa variação numa viagem típica.

Em vista dos peixes desembarcados por essas parelhas sofrerem estratificação a bordo, sendo separados em categorias de tamanhos (grandes, médios e pequenos), êste fator foi levado em consideração no trabalho.

Apesar de se lidar com os peixes desembarcados, surgiu a necessidade de verificar se há alguma diferença entre o comprimento médio dos peixes desembarcados e o dos capturados ou, em outras palavras, se ocorre rejeição no mar.

Por cortesia da "Sociedade de Pesca Taiyo Ltda." foi-nos permitido efetuar duas viagens a bordo de um dos seus barcos, durante as quais se observou a distribuição de comprimentos dos peixes capturados e, independentemente, fêz-se amostragem dos peixes desembarcados das duas viagens, no Entreposto de Santos. Dessa maneira pôde-se avaliar a técnica de amostragem aplicada no Entreposto.

\section{II - MÉTODOS}

O comprimento registrado foi o total (ponta do focinho à extremidade da cauda, ligeiramente estendida), tendo-se usado uma régua de madeira graduada de $0,50 \mathrm{em} 0,50 \mathrm{~cm}$. A leitura foi feita no meio centímetro inferior (por exemplo: 25,00 a 25,49 $\mathrm{cm}=25,00 \mathrm{~cm})$. Na análise dos dados de cada amostra as classes de $0,50 \mathrm{~cm}$ foram agrupadas em classes de $1,00 \mathrm{~cm}$ ( $\mathrm{cm}$ inferior, ou seja, as classes de 25,00 a $25,99 \mathrm{~cm}$, por exemplo, foram agrupadas na de $25,00 \mathrm{~cm}$ ), não tendo sido levado em consideração o fator de correção de $0,50 \mathrm{~cm}$.

Os barcos efetuam diversos lances até preencher os porões. Com o fito de verificar se de fato a amostragem estratificada está representando a captura de todos os lances da parelha foi obtida uma amostra ao acaso, de peixes a granel, de diversos lances. Os comprimentos e as freqüências de cada uma dessas amostras, bem como a respectiva média, variância da média e êrro padrão da média, foram lançados na Tabela I. As áreas onde foram efetuados os lances constam na Figura 1. 


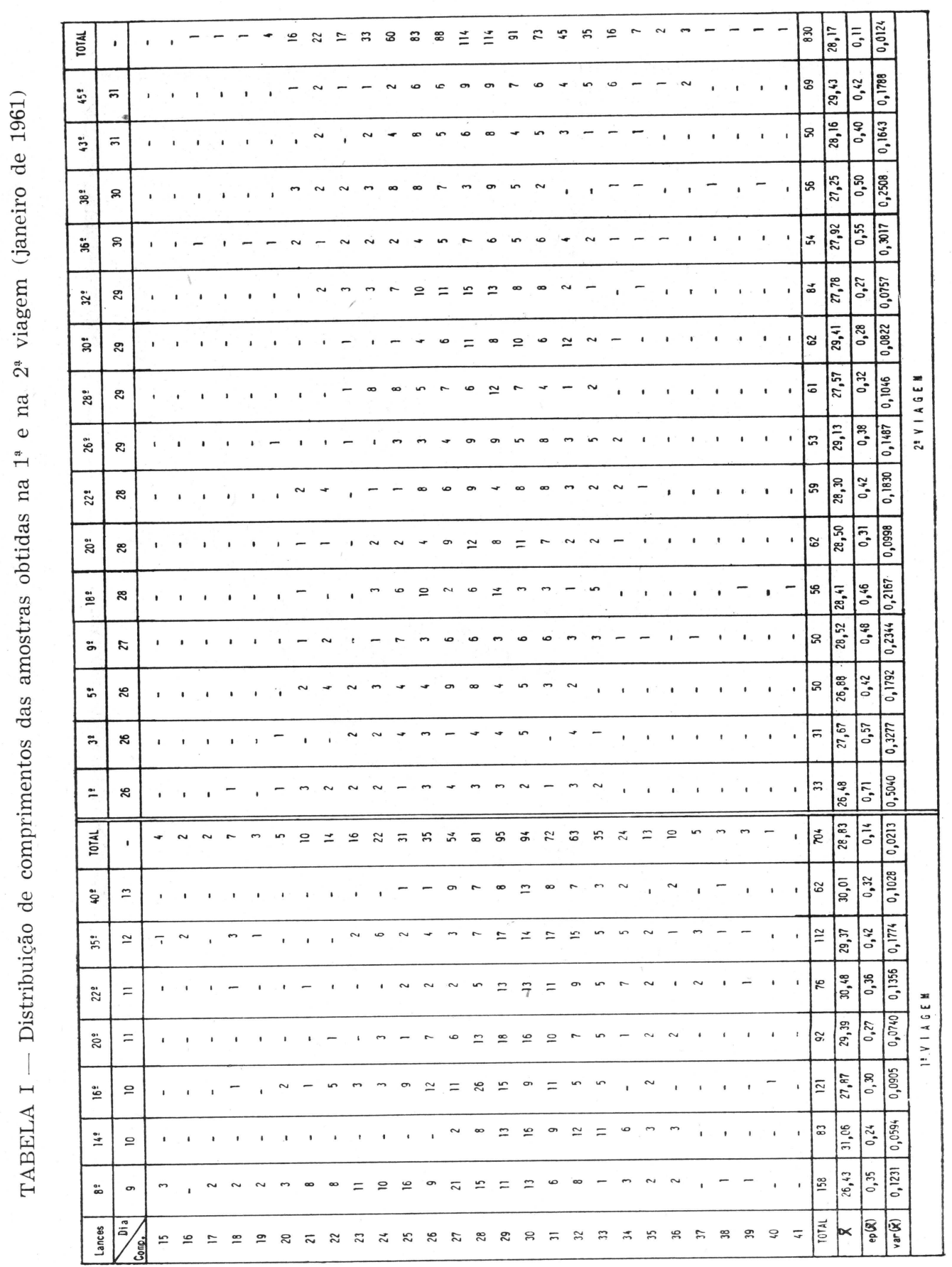




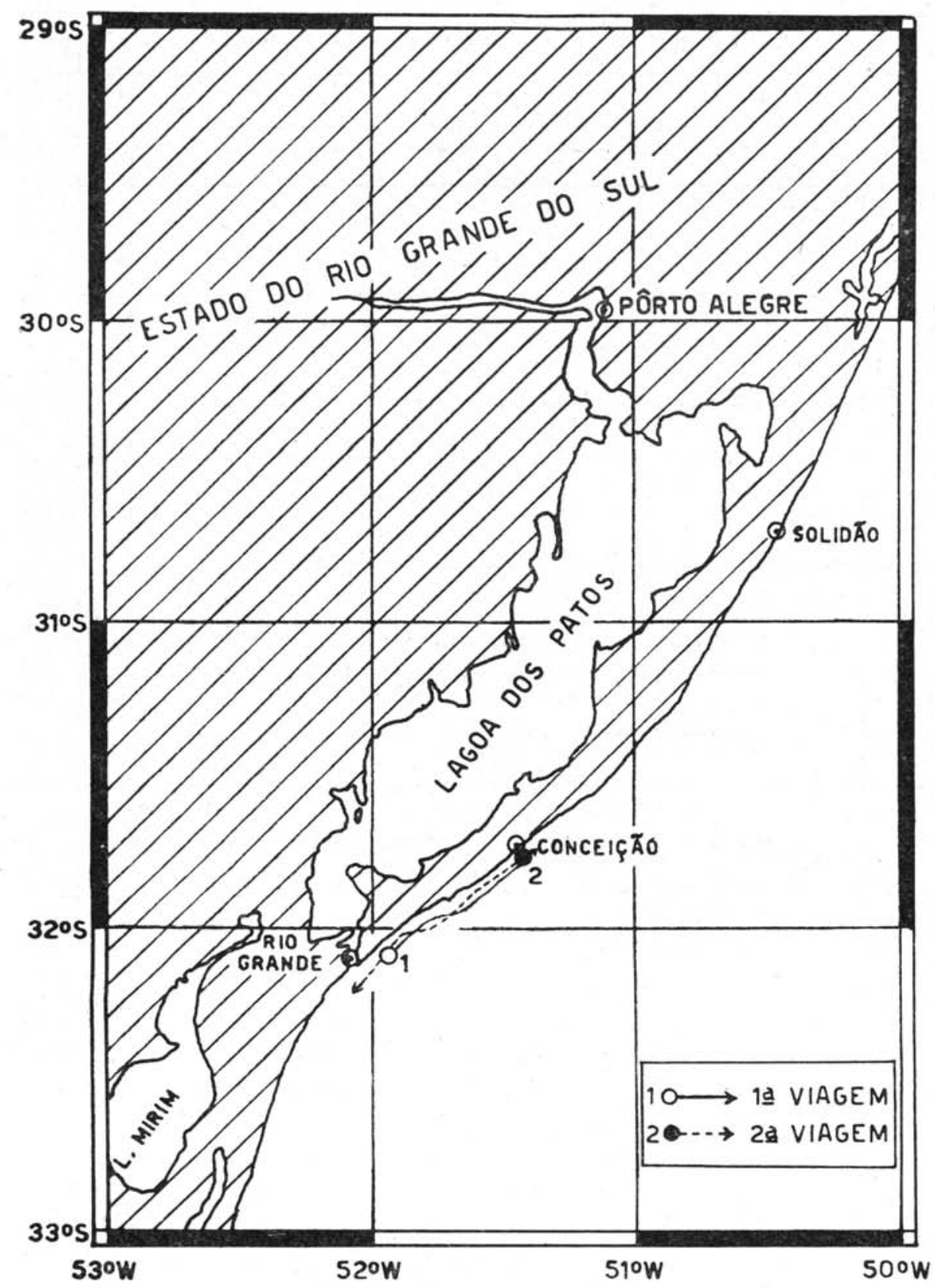

Fig. 1 - Locais onde foram efetuados os lances. 
Essas amostras foram reunidas numa só, constituindo uma amostra grande, sendo uma da primeira viagem e, outra, da segunda, tendo-se feito comparação do seu comprimento médio com o comprimento médio geral da amostragem estratificada obtida após o retôrno de cada viagem, como se pode verificar pela Tabela IX (veja-se o cálculo para a obtenção do comprimento médio geral na Tabela VIII). O comprimento médio da amostra grande, tanto aquela da primeira quanto da segunda viagem, foi comparado, respectivamente, com o comprimento médio das duas amostras estratificadas da primeira viagem, e com o comprimento médio das três amostras estratificadas da segunda viagem (Tabela $\mathrm{X}$ ).

Com o fito de verificar se há, ou não, diferença no comprimento médio por categoria de tamanho, resolveu-se efetuar a medição dos peixes contidos em três caixas de cada categoria, sendo a primeira no início, a segunda no meio e, a terceira, no fim da descarga. Em alguns casos não foi possível a obtenção da caixa do início.

Finalmente, os peixes medidos por categoria (cada caixa continha $25 \mathrm{~kg}$ de peixes) foram reunidos, tendo-se obtido o comprimento médio geral (veja o cálculo para a sua obtenção na Tabela VIII). Isto foi feito para os peixes obtidos no início, no meio e no fim da descarga. As comparações feitas entre êsses comprimentos médios gerais constam na Tabela V.

\section{III - RESULTADOS}

1 - Amostragem por lance

Os comprimentos médios das amostras obtidas de vários lances, relacionados na Tabela I, foram lançados em dois gráficos: um (Fig. 2) referente à primeira viagem e, outro (Fig. 3), à segunda.

O comprimento médio de cada lance foi comparado com o dos seguintes, a fim de se verificar qual a probabilidade de cada um pertencer à mesma população. O método empregado foi o do teste $t$, de fórmula:

onde:

$$
t=\frac{\bar{x}_{a}-\bar{x}_{b}}{\sqrt{S_{\bar{x}_{a}}^{2}+S_{\bar{s}_{b}}^{2}}}
$$

$$
\begin{aligned}
& t=\text { coeficiente do teste } \\
& \bar{x}_{a}=\text { comprimento médio maior }
\end{aligned}
$$




$$
\begin{aligned}
& \bar{x}_{b}=\text { comprimento médio menor } \\
& S_{x_{a}}^{2}=\text { variância da média maior } \\
& S_{x_{b}}^{2}=\text { variância da média menor }
\end{aligned}
$$

e os resultados constam na Tabela II (primeira viagem) e na Tabela III (segunda viagem).

\begin{tabular}{|c|c|c|c|c|c|c|c|}
\hline \multicolumn{2}{|c|}{ Lances } & $14^{\circ}$ & $16^{\circ}$ & $20^{\circ}$ & $22^{\circ}$ & $35^{\circ}$ & $400^{\circ}$ \\
\hline 8 & $\begin{array}{l}t \\
P\end{array}$ & $\begin{array}{r}11,02 \\
<0,01\end{array}$ & $\begin{array}{r}3,13 \\
<0,01\end{array}$ & $\begin{array}{r}6,72 \\
<0,01\end{array}$ & $\begin{array}{r}8,10 \\
<\quad 0,01\end{array}$ & $\begin{array}{r}5,44 \\
<0,01\end{array}$ & $\begin{array}{r}7,61 \\
<0,01\end{array}$ \\
\hline $14^{\circ}$ & $\begin{array}{l}t \\
P\end{array}$ & - & $\begin{array}{r}8,39 \\
<0,01\end{array}$ & $\begin{array}{r}4,63 \\
<0,01\end{array}$ & $\begin{array}{r}1,31 \\
>0,05\end{array}$ & $\begin{array}{r}3,52 \\
<0,01\end{array}$ & $\begin{array}{r}2,62 \\
\simeq 0,01\end{array}$ \\
\hline $16^{\circ}$ & $\begin{array}{l}t \\
P\end{array}$ & - & - & $\begin{array}{r}3,80 \\
<0,01\end{array}$ & $\begin{array}{r}5,55 \\
<0,01\end{array}$ & $\begin{array}{r}2,94 \\
\cong 0,01\end{array}$ & $\begin{array}{r}4,86 \\
<0,01\end{array}$ \\
\hline $20{ }^{\circ}$ & $\begin{array}{l}t \\
P\end{array}$ & 一 & - & - & $\begin{array}{r}2,42 \\
>0,01\end{array}$ & $\begin{array}{r}0,04 \\
>0,05\end{array}$ & $\begin{array}{r}1,47 \\
>0,05\end{array}$ \\
\hline 22 。 & $\begin{array}{l}t \\
P\end{array}$ & - & - & - & - & $\begin{array}{r}1,98 \\
\cong 0,05\end{array}$ & $\begin{array}{r}0,97 \\
>0,05\end{array}$ \\
\hline $35^{\circ}$ & $\begin{array}{l}t \\
P\end{array}$ & - & - & - & - & - & $\begin{array}{r}1,20 \\
>0,05\end{array}$ \\
\hline
\end{tabular}

TABELA II - Comparação do comprimento médio das amostras obtidas na primeira viagem, com a aplicação do teste $t$

$t=$ coeficiente do teste; $P=$ probabilidade.

Na comparação do comprimento médio da amostra de cada lance referente à primeira viagem (Tabela II) notam-se valôres altos de $t$, indicando baixa probabilidade de cada média pertencer à mesma população. Costuma-se aceitar como insignificantes as diferenças entre amostras com probabilidades acima de 0,05 e significantes as abaixo de 0,05. Pela Figura 2, onde se acham lançados êsses comprimentos médios, verifica-se fàcilmente que êsse resultado era de se esperar, pois de modo geral apresentam diferenças muito grandes, exceto os quatro últimos. 


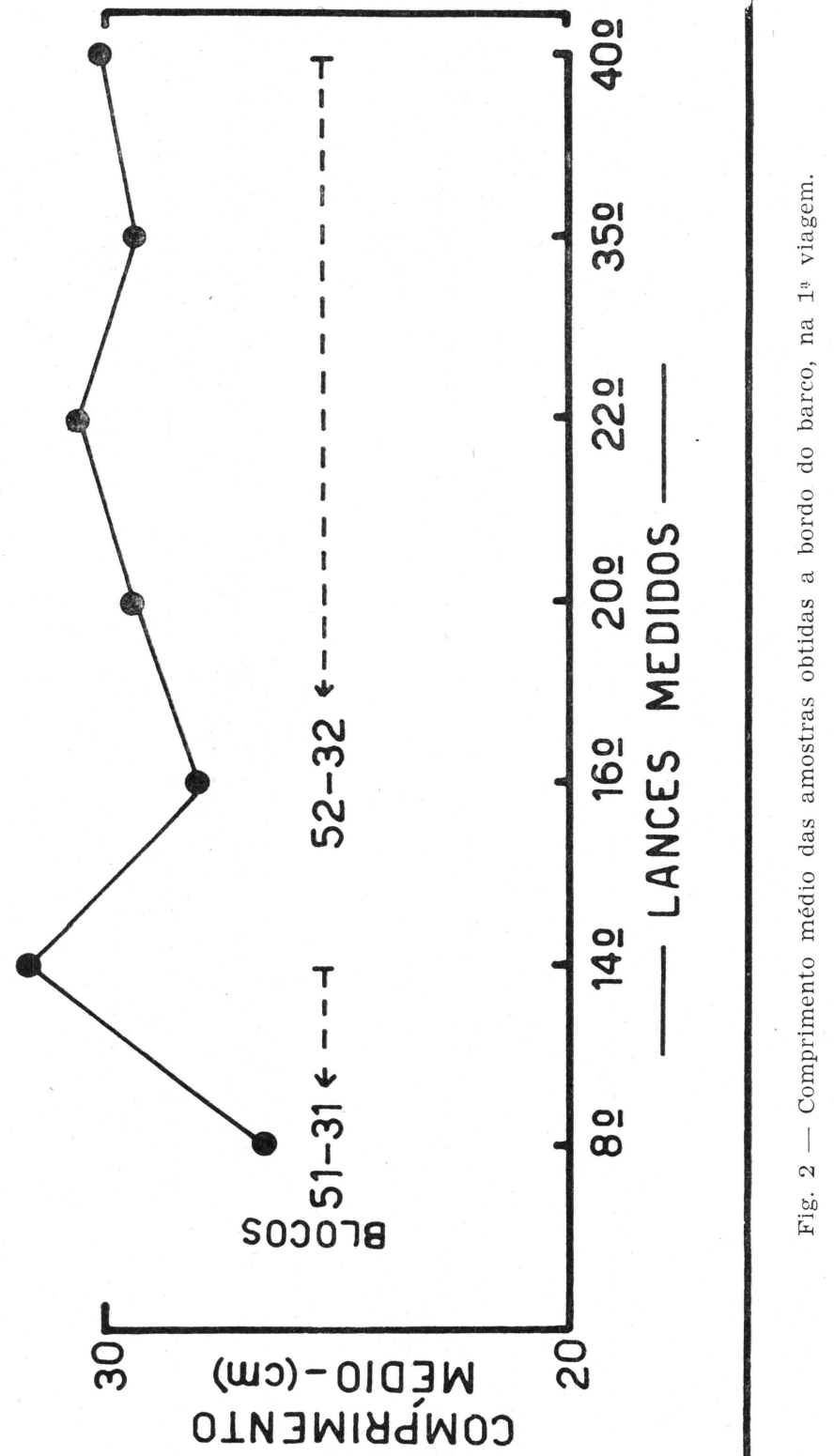


$-14-$

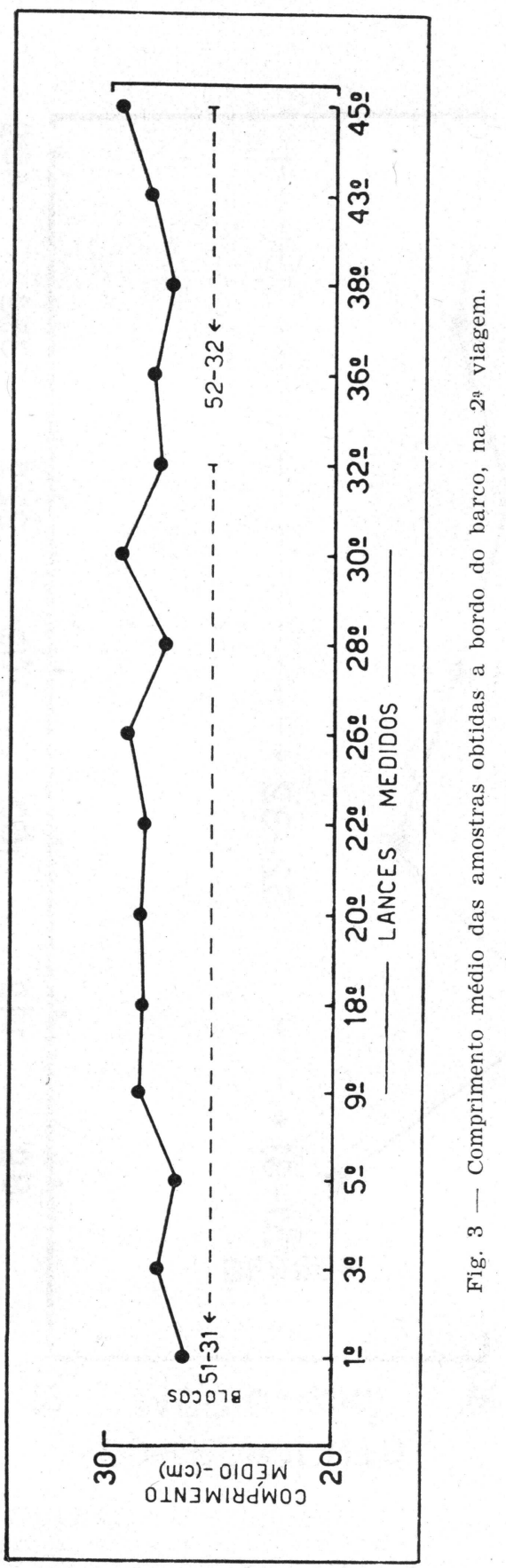


A bordo do barco observou-se que os lances efetuados próximos à costa traziam pescadas-foguetes pequenas; os efetuados um pouco mais além traziam peixes de porte médio e, mais adiante (cêrca de 3 a 5 milhas náuticas da costa) o contingente maior era constituído por peixes de porte grande. Nesta primeira viagem houve variação sensível entre os lances efetuados perto e distantes (entre 2 e 5 milhas náuticas) da costa, nas proximidades das cidades de Conceição e Rio Grande, situadas em dois blocos de pesca (60 min de lado) : 51-31 e 52-32). Os primeiros lances foram efetuados como tentativa para a localização dos cardumes.

$\mathrm{Na}$ segunda viagem a variação entre o comprimento médio de cada amostra com o de outras não foi tão acentuada (Fig. 3) justamente porque a pesca se realizou numa faixa paralela à costa, distante dela 3 a 4 milhas náuticas, nas proximidades das mesmas cidades antes mencionadas, localizadas nos mesmos blocos também citados. Conforme se pode notar pelo exame da Tabela III, grande

TABELA III - Comparação do comprimento médio das amostras obtidas na segunda viagem, com a aplicação do teste $t$

\begin{tabular}{|c|c|c|c|c|c|c|c|c|c|c|c|c|c|c|c|}
\hline \multicolumn{2}{|c|}{ LANCES } & 38 & $5^{2}$ & $9 ?$ & 189 & 209 & $22^{\circ}$ & $26^{\circ}$ & $28{ }^{\circ}$ & $30^{\circ}$ & $32^{\circ}$ & $35^{\circ}$ & $38^{\circ}$ & $43^{\circ}$ & 459 \\
\hline 19 & $\begin{array}{l}t \\
p\end{array}$ & $\begin{array}{r}1,30 \\
>0,05 \\
\end{array}$ & $\begin{array}{r}0,48 \\
>0,05 \\
\end{array}$ & $\begin{array}{r}2,40 \\
>0,01 \\
\end{array}$ & $\begin{array}{r}2,29 \\
>0,01 \\
\end{array}$ & $\begin{array}{r}2,62 \\
>0,01 \\
\end{array}$ & $\begin{array}{r}2,21 \\
>0,01 \\
\end{array}$ & $\begin{array}{r}3,31 \\
<0,01 \\
\end{array}$ & $\begin{array}{r}1,41 \\
>0,05 \\
\end{array}$ & $\begin{array}{r}3,85 \\
<0,01 \\
\end{array}$ & $\begin{array}{r}1,71 \\
>0,05 \\
\end{array}$ & $\begin{array}{r}1,51 \\
>0,05 \\
\end{array}$ & $\begin{array}{r}0,88 \\
>0,05 \\
\end{array}$ & $\begin{array}{r}2,07 \\
>0,01 \\
\end{array}$ & $\begin{array}{r}3,59 \\
<0,01 \\
\end{array}$ \\
\hline 39 & $\begin{array}{l}t \\
p \\
\end{array}$ & - & $\begin{array}{r}1,11 \\
>0,05 \\
\end{array}$ & $\begin{array}{r}1,13 \\
>0,05 \\
\end{array}$ & $\begin{array}{r}1,01 \\
>0,05 \\
\end{array}$ & $\begin{array}{r}1,27 \\
20,05 \\
\end{array}$ & $\begin{array}{r}0,88 \\
>0,05 \\
\end{array}$ & $\begin{array}{r}2,11 \\
>0,01 \\
\end{array}$ & $\begin{array}{r}0,15 \\
>0,05 \\
\end{array}$ & $\begin{array}{r}2,71 \\
<0,01 \\
\end{array}$ & $\begin{array}{r}0,17 \\
20,05 \\
\end{array}$ & $\begin{array}{r}0,31 \\
>0,05 \\
\end{array}$ & $\begin{array}{r}0,55 \\
>0,05 \\
\end{array}$ & $\begin{array}{r}0,70 \\
>0,05 \\
\end{array}$ & $\begin{array}{r}2,47 \\
>0,01 \\
\end{array}$ \\
\hline 59 & $\begin{array}{l}t \\
p \\
p\end{array}$ & - & $\therefore$ & $\begin{array}{r}2,56 \\
\times 0,01 \\
\end{array}$ & $\begin{array}{r}2,46 \\
>0,01 \\
\end{array}$ & $\begin{array}{r}3,11 \\
<0,01 \\
\end{array}$ & $\begin{array}{r}2,36 \\
>0,01 \\
\end{array}$ & $\begin{array}{r}3,94 \\
<0,01 \\
\end{array}$ & $\begin{array}{r}1,30 \\
\times 0,05 \\
\end{array}$ & $\begin{array}{r}4,06 \\
<0,01 \\
\end{array}$ & $\begin{array}{r}1,80 \\
>0,05\end{array}$ & $\begin{array}{r}1,50 \\
>0,05\end{array}$ & $\begin{array}{r}0,56 \\
>0,05\end{array}$ & $\begin{array}{r}2,20 \\
>0,01\end{array}$ & $\begin{array}{r}4,32 \\
<0,01 \\
\end{array}$ \\
\hline 92 & $\begin{array}{l}\mathrm{t} \\
\mathrm{p}\end{array}$ & - & - & - & $\begin{array}{r}0,16 \\
>0,05 \\
\end{array}$ & $\begin{array}{r}0,03 \\
>0,05 \\
\end{array}$ & $\begin{array}{r}0,34 \\
20,05 \\
\end{array}$ & $\begin{array}{r}1,00 \\
>0,05 \\
\end{array}$ & $\begin{array}{r}1,63 \\
>0,05 \\
\end{array}$ & $\begin{array}{r}1,58 \\
>0,05 \\
\end{array}$ & $\begin{array}{r}1,32 \\
>0,05 \\
\end{array}$ & $\begin{array}{r}0,82 \\
>0,05 \\
\end{array}$ & $\begin{array}{r}1,84 \\
>0,05 \\
\end{array}$ & $\begin{array}{r}0,57 \\
>0,05 \\
\end{array}$ & $\begin{array}{r}1,42 \\
>0,05 \\
\end{array}$ \\
\hline 189 & $\begin{array}{l}t \\
p\end{array}$ & - & - & - & - & $\begin{array}{r}0,16 \\
>0,05 \\
\end{array}$ & $\begin{array}{r}0,17 \\
>0,05 \\
\end{array}$ & $\begin{array}{r}1,20 \\
>0,05 \\
\end{array}$ & $\begin{array}{r}1,50 \\
>0,05 \\
\end{array}$ & $\begin{array}{r}1,85 \\
>0,05 \\
\end{array}$ & $\begin{array}{r}1,16 \\
>0,05 \\
\end{array}$ & $\begin{array}{r}0,68 \\
>0,05 \\
\end{array}$ & $\begin{array}{r}1,70 \\
>0,05 \\
\end{array}$ & $\begin{array}{r}0,40 \\
>0,05 \\
\end{array}$ & $\begin{array}{r}1,64 \\
>0,05 \\
\end{array}$ \\
\hline 209 & $\begin{array}{l}t \\
p\end{array}$ & - & - & - & - & - & $\begin{array}{r}0,37 \\
>0,05 \\
\end{array}$ & $\begin{array}{r}1,28 \\
>0,05 \\
\end{array}$ & $\begin{array}{r}2,06 \\
>0,01 \\
\end{array}$ & $\begin{array}{r}2,16 \\
>0,01 \\
\end{array}$ & $\begin{array}{r}1,71 \\
>0,05 \\
\end{array}$ & $\begin{array}{r}0,92 \\
>0,05 \\
\end{array}$ & $\begin{array}{r}2,11 \\
>0,01 \\
\end{array}$ & $\begin{array}{r}0,66 \\
>0,05 \\
\end{array}$ & $\begin{array}{r}1,78 \\
>0,05 \\
\end{array}$ \\
\hline 229 & $\begin{array}{l}t \\
p \\
\end{array}$ & - & - & - & - & - & - & $\begin{array}{r}1,45 \\
>0,05 \\
\end{array}$ & $\begin{array}{r}1,37 \\
>0,05 \\
\end{array}$ & $\begin{array}{r}2,17 \\
>0,01 \\
\end{array}$ & $\begin{array}{r}1,04 \\
>0,05 \\
\end{array}$ & $\begin{array}{r}0,55 \\
>0,05 \\
\end{array}$ & $\begin{array}{r}1,51 \\
>0,05 \\
\end{array}$ & $\begin{array}{r}0,24 \\
>0,05 \\
\end{array}$ & $\begin{array}{r}1,88 \\
>0,05 \\
\end{array}$ \\
\hline 269 & \begin{tabular}{|l}
$t$ \\
$p$ \\
\end{tabular} & . & - & - & - & - & - & - & $\begin{array}{r}3,12 \\
<0,01 \\
\end{array}$ & $\begin{array}{r}0,58 \\
>0,05 \\
\end{array}$ & $\begin{array}{r}2,87 \\
<0,01 \\
\end{array}$ & $\begin{array}{r}1,80 \\
>0,05 \\
\end{array}$ & $\begin{array}{r}2,98 \\
<0,01 \\
\end{array}$ & $\begin{array}{r}1,73 \\
>0,05 \\
\end{array}$ & $\begin{array}{r}0,52 \\
>0,05 \\
\end{array}$ \\
\hline 289 & $\begin{array}{l}t \\
p \\
\end{array}$ & - & - & - & - & - & - & - & - & $\begin{array}{r}4,27 \\
<0,01 \\
\end{array}$ & $\begin{array}{r}0,50 \\
20,05 \\
\end{array}$ & $\begin{array}{r}0,55 \\
>0,05 \\
\end{array}$ & $\begin{array}{r}0,54 \\
>0,05 \\
\end{array}$ & $\begin{array}{r}1,15 \\
>0,05 \\
\end{array}$ & $\begin{array}{r}3,50 \\
<0,01 \\
\end{array}$ \\
\hline 300 & $\begin{array}{l}t \\
p\end{array}$ & - & - & - & - & - & - & - & - & - & $\begin{array}{r}4,17 \\
<0,01 \\
\end{array}$ & $\begin{array}{r}2,44 \\
>0,01 \\
\end{array}$ & $\begin{array}{r}3,78 \\
<0,01 \\
\end{array}$ & $\begin{array}{r}2,55 \\
>0,01 \\
\end{array}$ & $\begin{array}{r}0,03 \\
>0,05 \\
\end{array}$ \\
\hline $32^{\circ}$ & $\begin{array}{l}t \\
p\end{array}$ & $\cdot$ & - & - & - & - & . & - & - & - & - & $\begin{array}{r}0,22 \\
>0,05 \\
\end{array}$ & $\begin{array}{r}0,92 \\
>0,05 \\
\end{array}$ & $\begin{array}{r}0,77 \\
>0,05 \\
\end{array}$ & $\begin{array}{r}3,30 \\
<0,01 \\
\end{array}$ \\
\hline 360 & \begin{tabular}{|l|}
$t$ \\
$p$ \\
\end{tabular} & - & - & - & - & - & - & - & - & - & - & - & $\begin{array}{r}0,90 \\
>0,05 \\
\end{array}$ & $\begin{array}{r}0,35 \\
>0,05 \\
\end{array}$ & $\begin{array}{r}2,18 \\
>0,01 \\
\end{array}$ \\
\hline 389 & $\begin{array}{l}t \\
p \\
\end{array}$ & - & - & - & - & - & $\cdot$ & - & - & - & $\cdot$ & - & - & $\begin{array}{r}1,42 \\
>0,05 \\
\end{array}$ & $\begin{array}{r}3,35 \\
<0,01 \\
\end{array}$ \\
\hline $43^{\circ}$ & $\begin{array}{l}t \\
p\end{array}$ & - & - & - & - & - & - & - & - & - & - & - & - & - & $\begin{array}{r}2,18 \\
>0,01\end{array}$ \\
\hline
\end{tabular}

$t=$ coeficiente do teste; $P=$ probabilidade. 
foi a probabilidade do comprimento médio de cada amostra pertencer à mesma população.

Em virtude do teste $t$ não avaliar a variabilidade de tôdas as amostras em conjunto (Croxton \& Cowden, 1952, p. 401), empregou-se a análise da variância, tendo-se determinado a variação "entre" e "dentro" das amostras, conforme se pode verificar pela Tabela IV. As fórmulas empregadas foram as seguintes:

$$
\begin{aligned}
& \text { v. d. }=\frac{\sum_{1}^{m}\left[\begin{array}{c}
n_{i} \\
\Sigma \\
1
\end{array}\left(x_{i}-\bar{x}_{i}\right)^{2}\right]}{\Sigma n_{i}-m} \\
& \text { v. e. }=\frac{\sum_{1}^{m}\left[n_{i}\left(\overline{x_{i}}-\bar{x}\right)^{2}\right]}{m-1}
\end{aligned}
$$

onde:

$$
\begin{aligned}
& \text { v. d. }=\text { variância "dentro" } \\
& \bar{x}_{i}=\text { média de uma coluna } \\
& x_{i}=\text { valor genérico } \\
& \bar{x}=\text { média geral } \\
& m=\text { número de colunas } \\
& n_{i}=\text { número de elementos } \\
& \text { v. e. }=\text { variância "entre" }
\end{aligned}
$$

\begin{tabular}{|c|c|c|c|c|c|c|}
\hline Viagem & $\begin{array}{c}\text { Fonte de varia- } \\
\text { câo }\end{array}$ & Variação & G.L. & Vàriância & $F$ & $P^{\prime}$ \\
\hline \multirow[t]{2}{*}{$1^{3}$} & $\begin{array}{l}\text { Dentro } \ldots \ldots \\
\text { Entre } \ldots \ldots \ldots\end{array}$ & $\begin{array}{l}8.753,34 \\
1.789,09\end{array}$ & $\begin{array}{r}697 \\
6\end{array}$ & \multirow[t]{2}{*}{$\begin{array}{r}12,55 \\
298,18\end{array}$} & \multirow[t]{2}{*}{23,75} & \multirow[t]{2}{*}{$<0,01$} \\
\hline & Total ....... & $10.542,43$ & 703 & & & \\
\hline \multirow{3}{*}{2} & \multirow{3}{*}{$\begin{array}{l}\text { Dentro } \ldots \ldots \ldots \\
\text { Entre } \ldots \ldots \ldots \\
\text { Total } \ldots \ldots \ldots \\
\end{array}$} & & 815 & & \multirow[t]{3}{*}{3,90} & \multirow[t]{3}{*}{$<0,01$} \\
\hline & & 541,54 & 14 & 38,68 & & \\
\hline & & $8.612,76$ & 829 & & & \\
\hline
\end{tabular}

TABELA IV - Análise da variância das amostras obtidas nas duas viagens

G.L. = grau de liberdade; $\mathrm{F}=$ razão da variância "entre" pela "dentro"; $\mathrm{P}=$ probabilidade. 
Nota-se que a variância "dentro" das amostras, nas duas viagens, apresenta valôres aproximadamente iguais, sendo menor na segunda viagem, e que a variância "entre" as amostras, na primeira viagem, é mais de sete vêzes maior que na segunda. Isto se deve ao fato de se ter obtido poucas amostras a bordo, na primeira viagem, o que pode ser observado pela comparação dos coeficientes $F$ obtidos.

\section{2 - Amostragem estratificada}

A análise dos dados referentes à amostragem estratificada consta na Tabela V. Os comprimentos médios da amostragem estratificada, referentes aos peixes contidos em duas ou três caixas de cada categoria de tamanho, foram comparados entre si por meio do teste $t$. Os números (1), (2) e (3) significam, respectivamente, o início, o meio e o fim da descarga.

Os peixes contidos em caixas da mesma categoria, medidos durante o desembarque, seja no início (1), no meio (2) ou no fim (3), apresentaram um comprimento médio que, na maioria das amostras, quando comparados pelo teste $t$, não mostraram diferenças significativas, ou seja, as probabilidades foram acima de 0,05 . Para graus de liberdade entre 100 e infinito, os valôres de $t$ para as probabilidades de 0,05 e 0,01 são, respectivamente: 1,98 e 1,96 e 2,63 e 2,58. Os valôres de $t$ cujas probabilidades foram menores do que 0,01 são em número de 17 , sendo os restantes 31 maiores do que 0,01 e 0,05. Conclui-se, portanto, que é necessário trabalhar com o conteúdo de mais do que uma caixa de cada categoria.

A análise da variância (Tabela VI) por categoria mostra a ocorrência da maior variabilidade com as caixas contendo peixes médios (quatro casos em que $P<0,01$ e quatro casos em que $P>$ $>0,01)$; em seguida três casos de peixes grandes em que $P<0,01$ e cinco casos em que $P>0,01$ e, peixes grandes, dois casos em que $P<0,01$ e seis casos em que $P>0,01$. Nos casos em que a variância "entre" excedeu significativamente à variância "dentro" diz-se que a diferença se deve a outros fatôres que não o acaso. Então pode-se supor que o aumento do tamanho (número de peixes) da amostra não redundará em diminuição da variância "dentro" das caixas, mas mantendo-se constante o número total de peixes a serem medidos de cada caixa e retirando-os de um número maior de caixas ao invés de uma só, a variância entre elas será reduzida. Assim, o coeficiente $F$ será baixo, aumentando a possibilidade das amostras apresentarem diferença não significativa. 


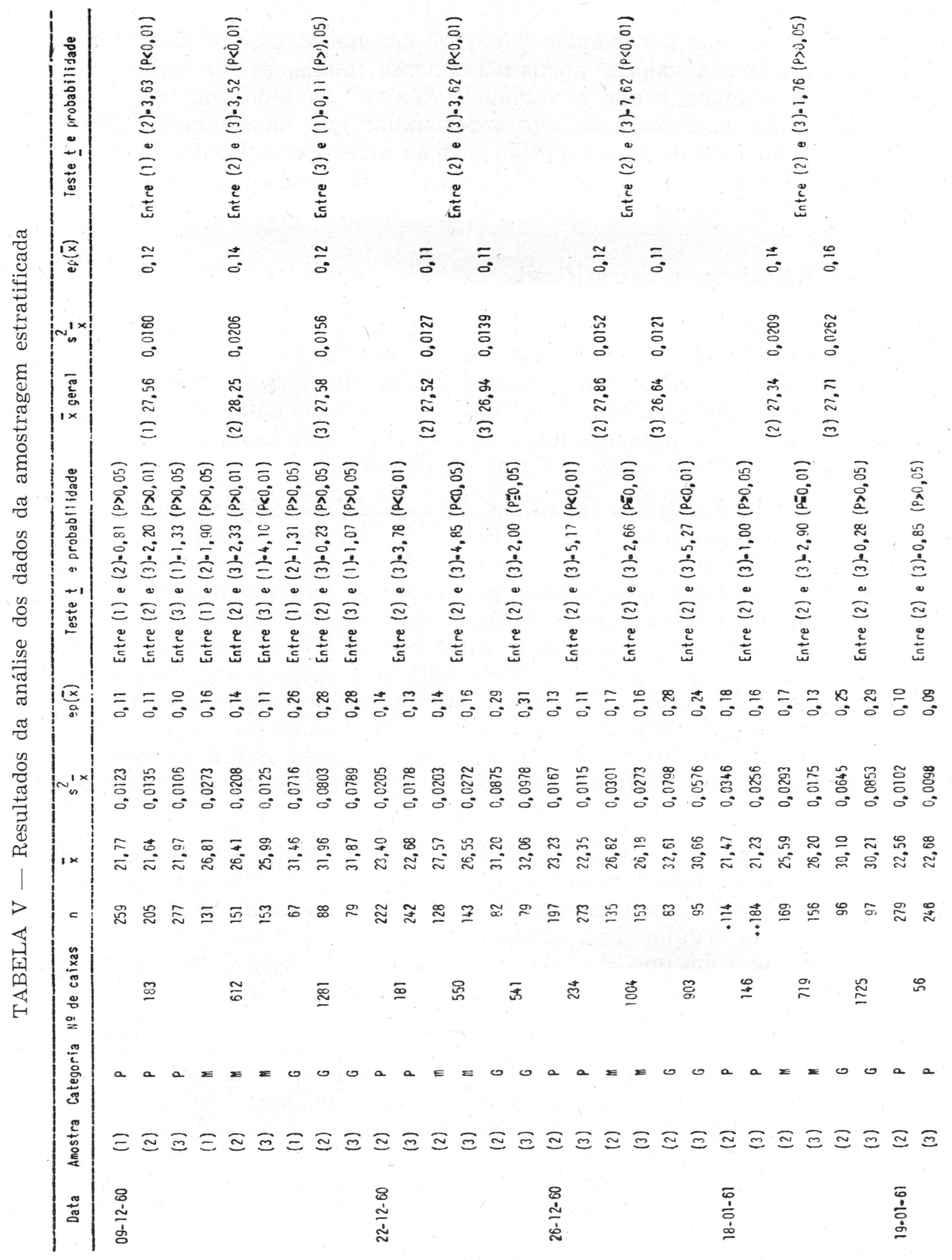




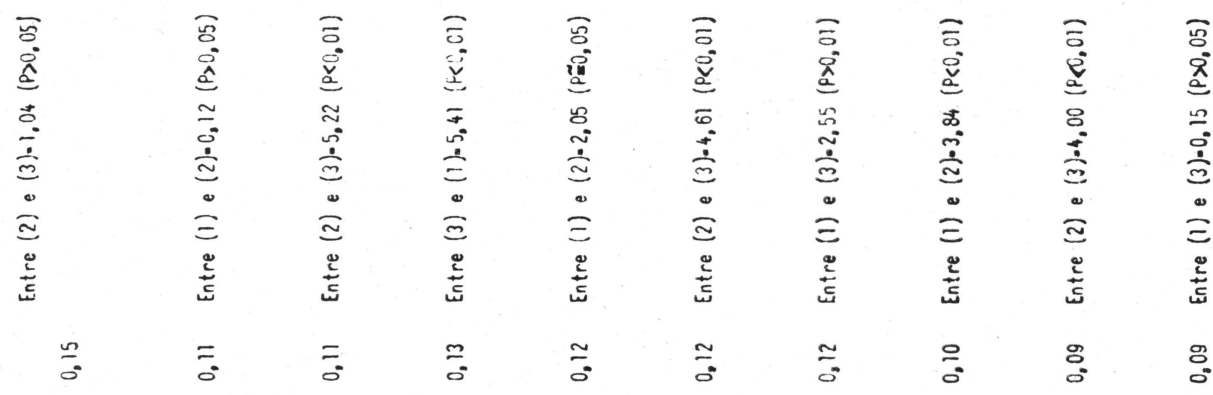

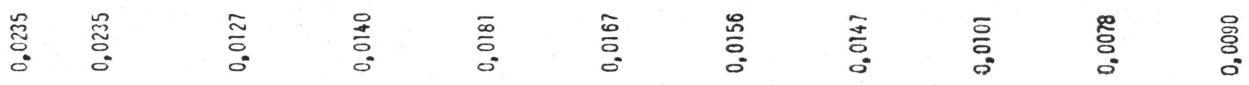

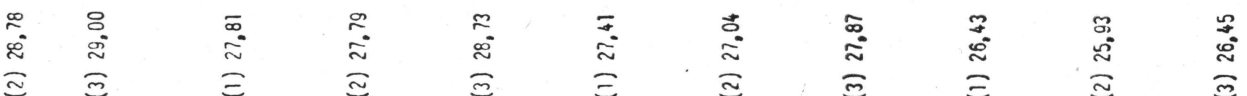

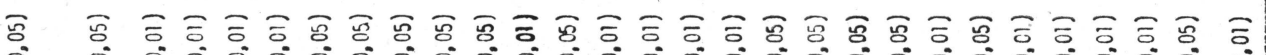

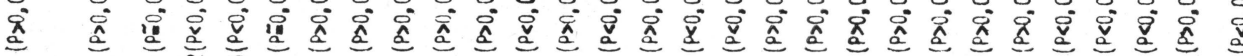
$0=\pi$ \%

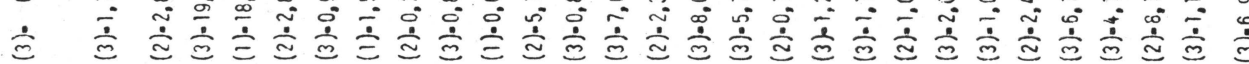

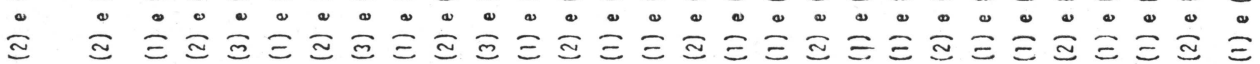

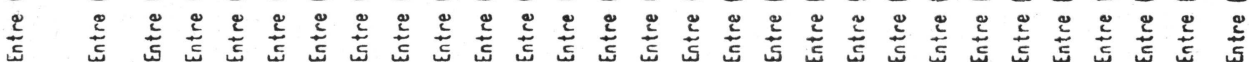

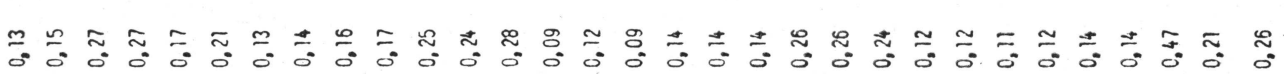

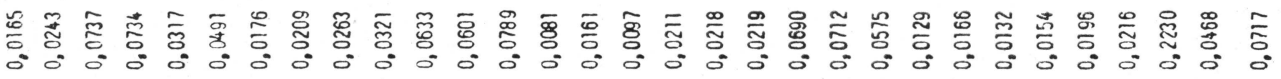
禺

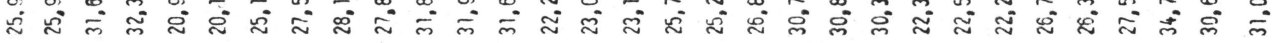
프

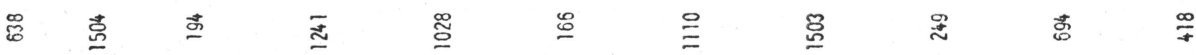

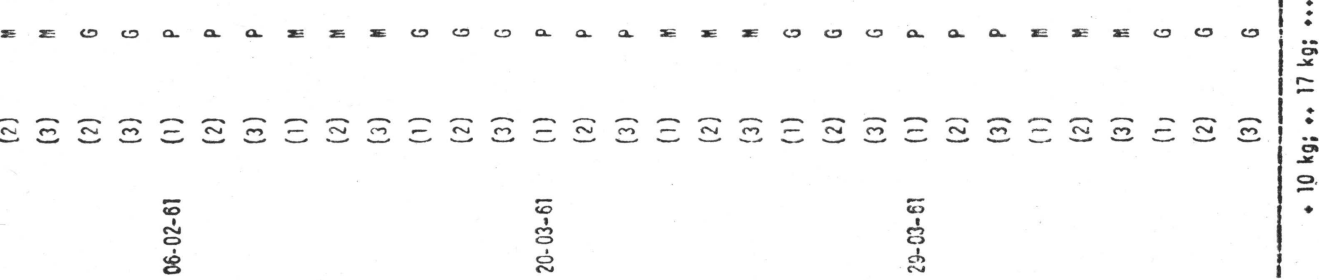




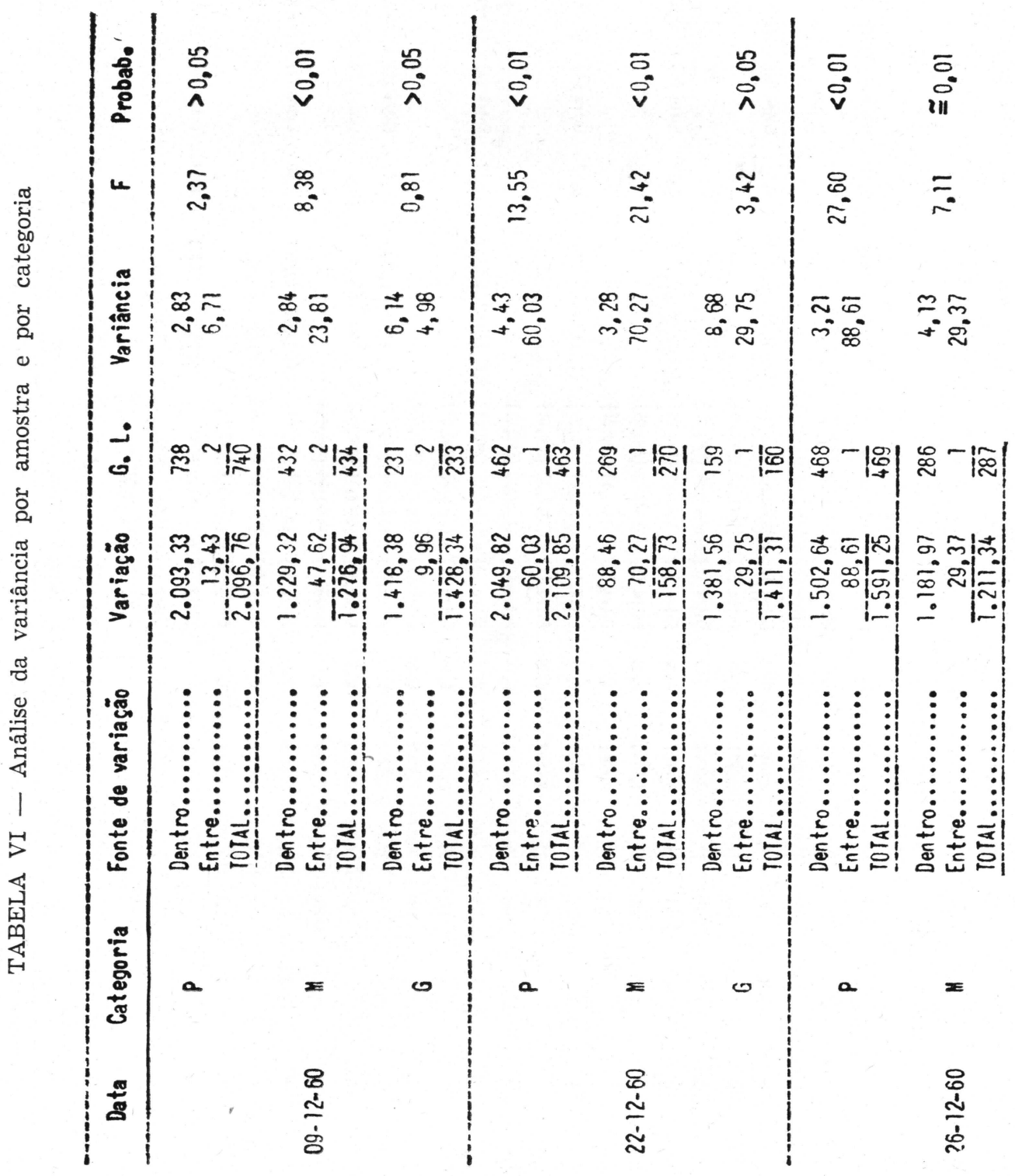




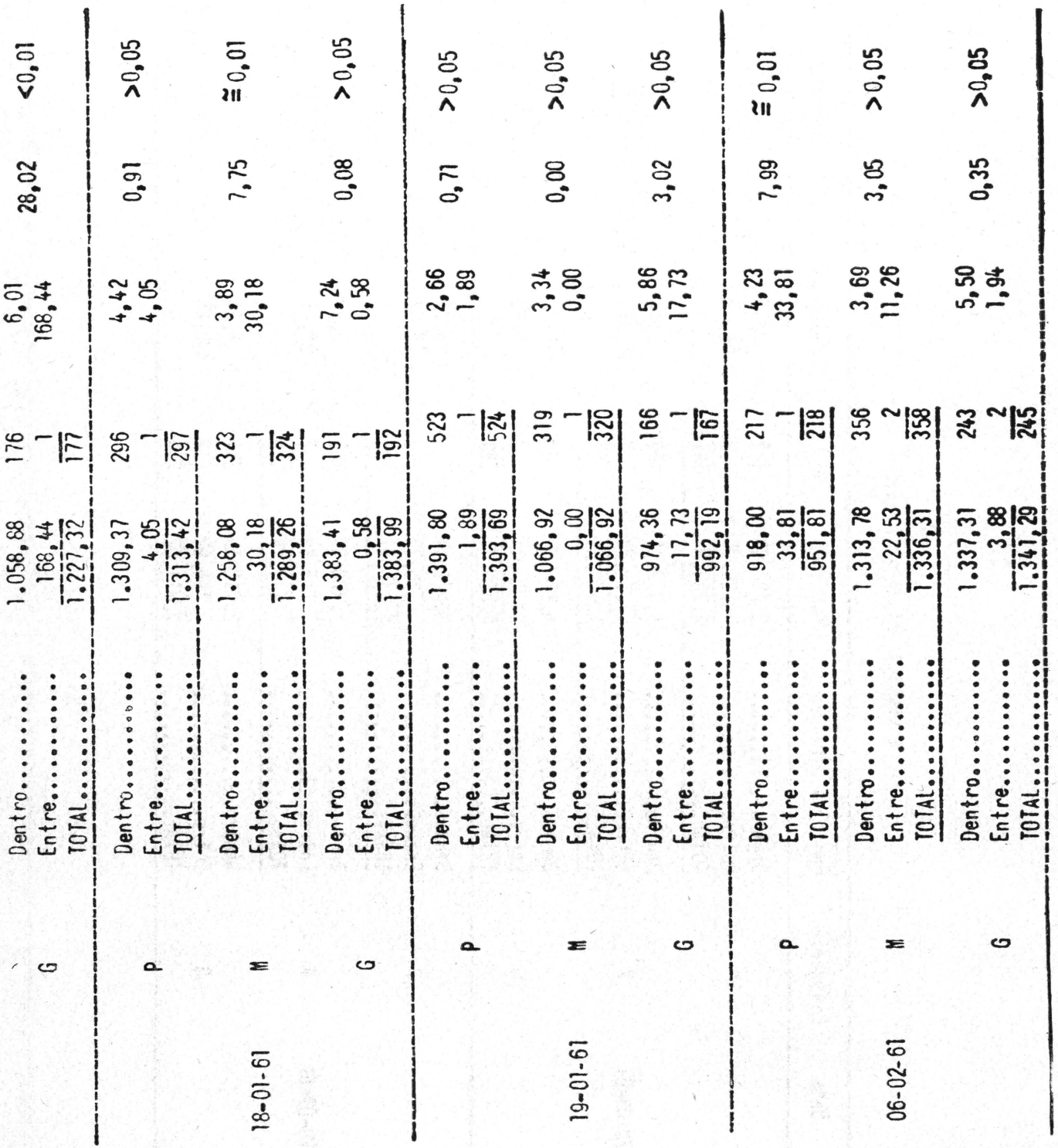




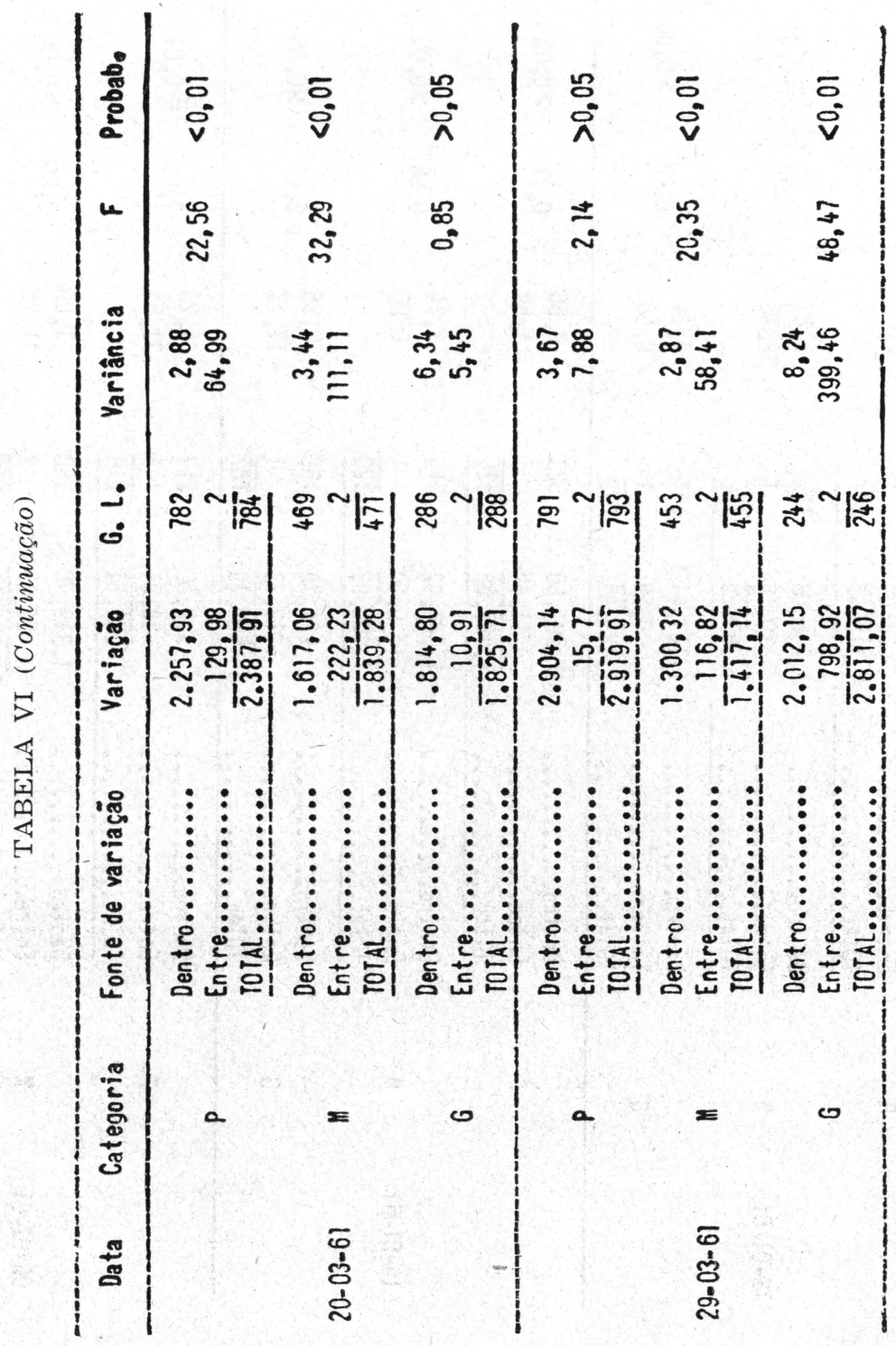


A análise da variância foi aplicada para se estimar a variabilidade "dentro" e "entre" as categorias, para tôdas as amostras (Tabela VI), tal como se vê na Tabela VII. Como era de se esperar, a variância "entre" é bem maior do que a variância "dentro", evidenciando ser grande a diferença entre as amostras obtidas, por categoria, provàvelmente devido ao fator tempo. Isto significa, òbviamente, que a distribuição de comprimentos varia mais entre viagens do que dentro de cada viagem.

TABELA VII - Análise da variância por categoria

\begin{tabular}{|c|c|c|c|c|c|c|}
\hline Categoria & $\begin{array}{c}\text { Fonte de varia- } \\
\text { ção }\end{array}$ & Variação & G.L. & Variância & $F$ & $P$ \\
\hline \multirow[t]{2}{*}{ P } & $\begin{array}{l}\text { Dentro } \ldots \ldots \ldots \\
\text { Entre } \ldots \ldots \ldots\end{array}$ & $\begin{array}{r}14.427,06 \\
2.006,62\end{array}$ & $\begin{array}{r}4443 \\
18\end{array}$ & \multirow[t]{2}{*}{$\begin{array}{r}32,47 \\
111,47\end{array}$} & \multirow[t]{2}{*}{3,43} & \multirow[t]{2}{*}{$<0,01$} \\
\hline & $\begin{array}{l}\text { Entre } \ldots \ldots \ldots \\
\text { Total } \ldots \ldots \ldots\end{array}$ & $16.433,68$ & 4461 & & & \\
\hline M & \multirow{2}{*}{$\begin{array}{l}\text { Entre } \ldots \ldots \ldots \\
\text { Total } \ldots \ldots \ldots\end{array}$} & $\begin{array}{l}9.852,12 \\
1.657,27\end{array}$ & $\begin{array}{r}2907 \\
19\end{array}$ & \multirow[t]{2}{*}{$\begin{array}{r}3,38 \\
87,22\end{array}$} & \multirow[t]{2}{*}{25,80} & \multirow[t]{2}{*}{$<0,01$} \\
\hline & & $11.509,39$ & 2926 & & & \\
\hline \multirow[t]{2}{*}{ G } & \multirow{2}{*}{$\begin{array}{r}\text { Entre } \ldots \ldots \ldots \\
\quad \text { Total } \ldots \ldots \ldots\end{array}$} & $\begin{array}{r}11.380,29 \\
1.721,67\end{array}$ & $\begin{array}{r}1696 \\
19\end{array}$ & \multirow[t]{2}{*}{$\begin{array}{r}6,71 \\
90,61\end{array}$} & \multirow[t]{2}{*}{13,50} & \multirow[t]{2}{*}{$<0,01$} \\
\hline & & $13.101,96$ & 1715 & & & \\
\hline
\end{tabular}

3 - Comprimento médio geral da amostragem estratificada

O comprimento médio das diversas amostras estratificadas foi obtido conforme o procedimento de Pope (1956, p. 18), exemplificado na Tabela VIII. Comparando-se as amostras estratificadas (Tabela V) do mesmo dia, entre si, não se encontrou diferença significativa em dois dos casos, mas significativa quando comparada com uma terceira, o que era de se esperar, tendo em vista o resultado declarado no item anterior.

$\mathrm{O}$ teste $t$ também foi empregado para comparar o comprimento médio geral das amostras obtidas em (1), (2) e (3), conforme pode-se verificar pelo exame da última coluna da Tabela V. O cálculo para a obtenção do comprimento médio geral vai exemplificado na Tabela VIII, com os dados da amostra estratificada (2), de 19-1-61. 


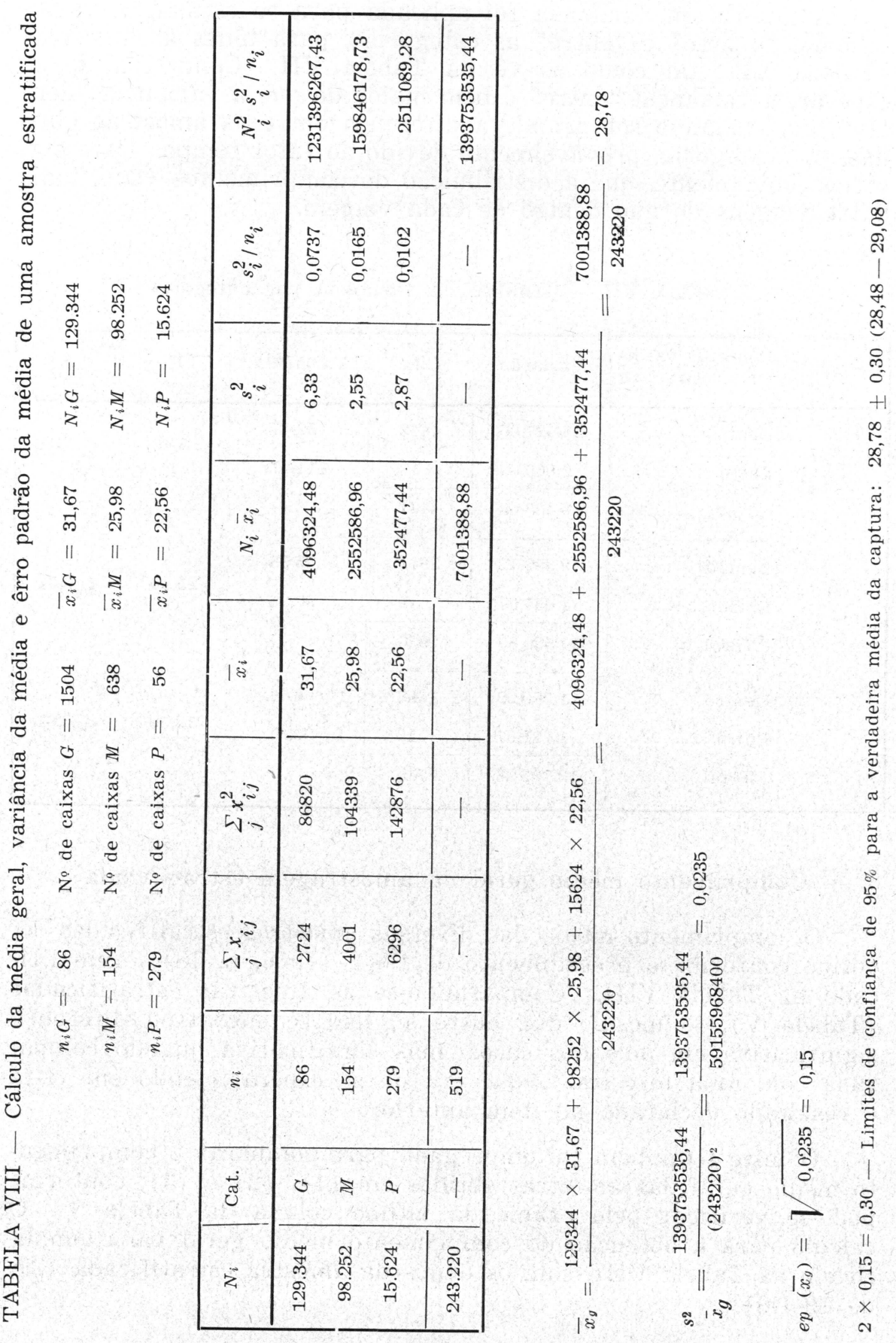


NotaÇÃo DA TABELA VIII - niG = número de peixes grandes medidos (1 caixa); $n i M=$ número de peixes médios medidos $(1$ caixa $) ; n i P=$ número de peixes pequenos medidos (1 caixa); número de caixas $G$ (peixes grandes desembarcados); número de caixas $M$ (peixes médios desembarcados); número de caixas $P$ (peixes pequenos desembarcados); $N i G=$ número de peixes grandes desembarcados; $N i M=$ número de peixes médios desembarcados; $N i P=$ número de peixes pequenos desembarcados; Cat. $=$ categoria de tamanho $(\mathrm{G}, \mathrm{M}, \mathrm{P}) ; \sum_{j} x_{i j}=$ somatória do comprimento multiplicado pela freqüência; $\Sigma x^{2}=$ somatória do comprimento elevado ao quadrado e multiplicado pela $j \quad i j$

freqüência; $\overline{x_{i}}=$ comprimento médio $(\mathrm{G}, \mathrm{M}, \mathrm{P}) ; N_{i} \overline{x_{i}}=$ número total de peixes desembarcados por categoria multiplicado pelo respectivo comprimento médio; $s_{i}^{2}=$ variância; $s_{i}^{2} / n_{i}=$ variância da média (variância dividida pelo número de peixes medidos (1 caixa) por categoria); $N_{i}^{2} s_{i}^{2} / n_{i}=$ número total de peixes desembarcados elevado ao quadrado, multiplicado pela variância e dividido pelo número de peixes medidos por categoria; $\overline{x_{g}}=$ média geral; $s_{x_{g}}^{2}=$ variância da média geral; ep $\left(\bar{x}_{g}\right)=$ êrro pađiño da média geral; $2(0,15)=0,30$, limites de confiança de $95 \%$ para a verdadeira média da captura, ou seja, 2 ep $\left(\overline{x_{g}}\right)$.

As sete amostras obtidas na primeira viagem foram englobadas, constituindo uma única, e seu comprimento médio foi comparado com o comprimento médio geral de (2) e (3) do dia 19-1-61, que fazem parte da amostragem estratificada feita no desembarque. Igualmente, as quinze amostras da segunda viagem foram englobadas, constituindo uma única, e seu comprimento médio foi comparado com o comprimento médio geral de (1), (2) e (3) da amostragem estratificada feita após o retôrno da viagem. Essa comparação pode ser vista na Tabela IX e Figuras 4 e 5, estas últimas referindo-se à distribuição percentual da freqüência dos comprimentos. A comparação entre as amostras obtidas a bordo e no Entreposto não seria elucidativa se apenas fôssem lançados os dados numéricos num gráfico, porque o número de peixes de cada amostra é diferente. Por isso determinou-se a porcentagem das respectivas freqüências, podendo-se fazer comparação mais significativa entre as curvas.

TABELA IX

\begin{tabular}{|c|c|c|c|c|c|c|c|}
\hline Dia & Amostra & $\bar{x}_{g}$ & $s_{\frac{2}{x}}^{2}$ & $\begin{array}{l}\text { Média das } \\
\text { amostras ob- } \\
\text { tidas a bordo }\end{array}$ & $s_{x}^{2}$ & Teste $t$ & Prob. \\
\hline $19-1-61$ & $\begin{array}{l}(2) \\
(3)\end{array}$ & $\begin{array}{l}28,78 \\
29,00\end{array}$ & $\begin{array}{l}0,0235 \\
0,0235\end{array}$ & 28,83 & 0,0213 & $\begin{array}{l}0,23 \\
0,80\end{array}$ & $\begin{array}{l}>0,05 \\
>0,05\end{array}$ \\
\hline $6-2-61$ & $\begin{array}{l}(1) \\
(2) \\
(3)\end{array}$ & $\begin{array}{l}27,81 \\
27,79 \\
28,73\end{array}$ & $\begin{array}{l}0,0127 \\
0,0140 \\
0,0181\end{array}$ & 28,17 & 0,0124 & $\begin{array}{l}2,25 \\
2,37 \\
3,29\end{array}$ & $\begin{array}{l}>0,01 \\
>0,01 \\
<0,01\end{array}$ \\
\hline
\end{tabular}




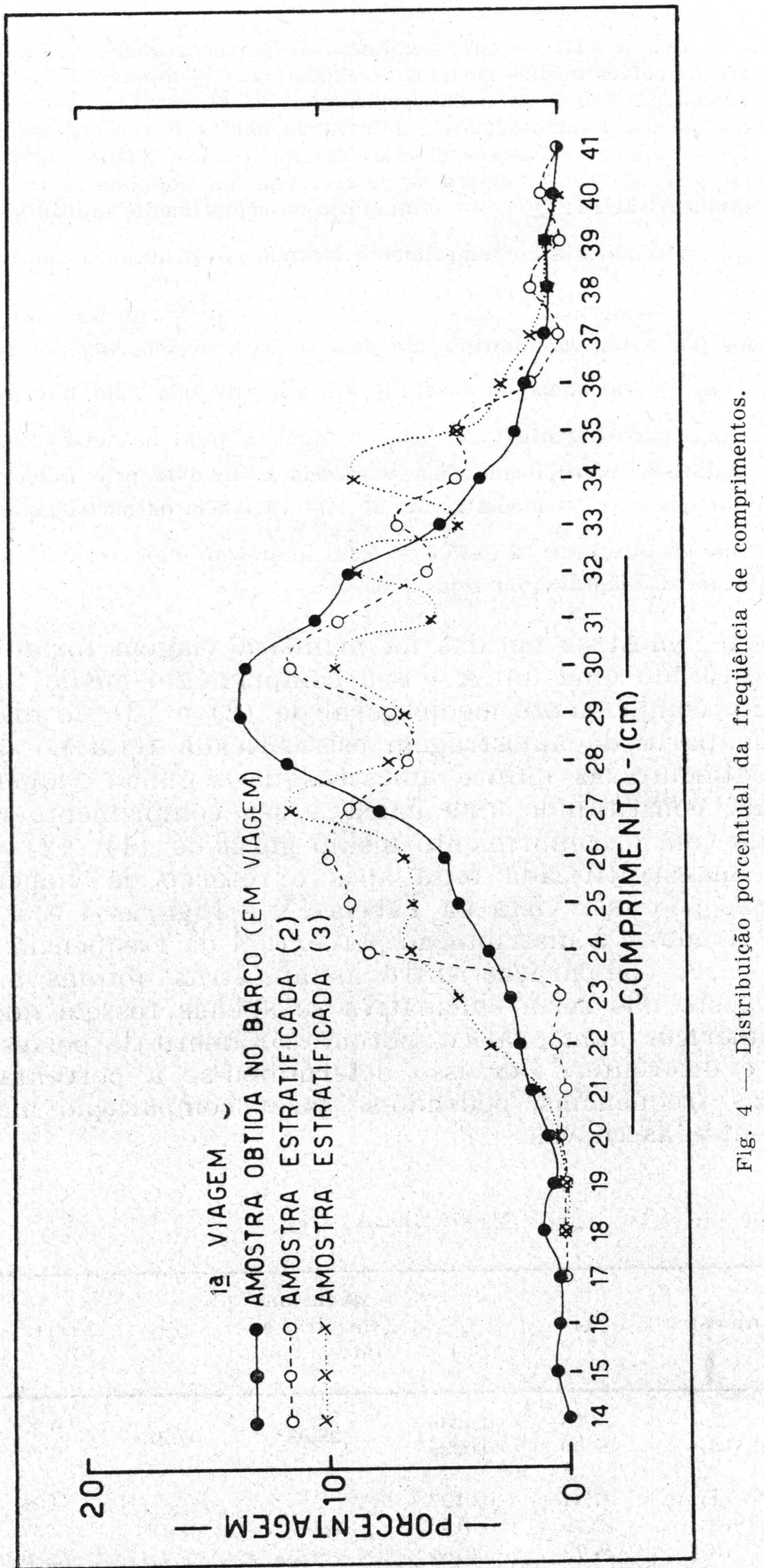


$-27-$

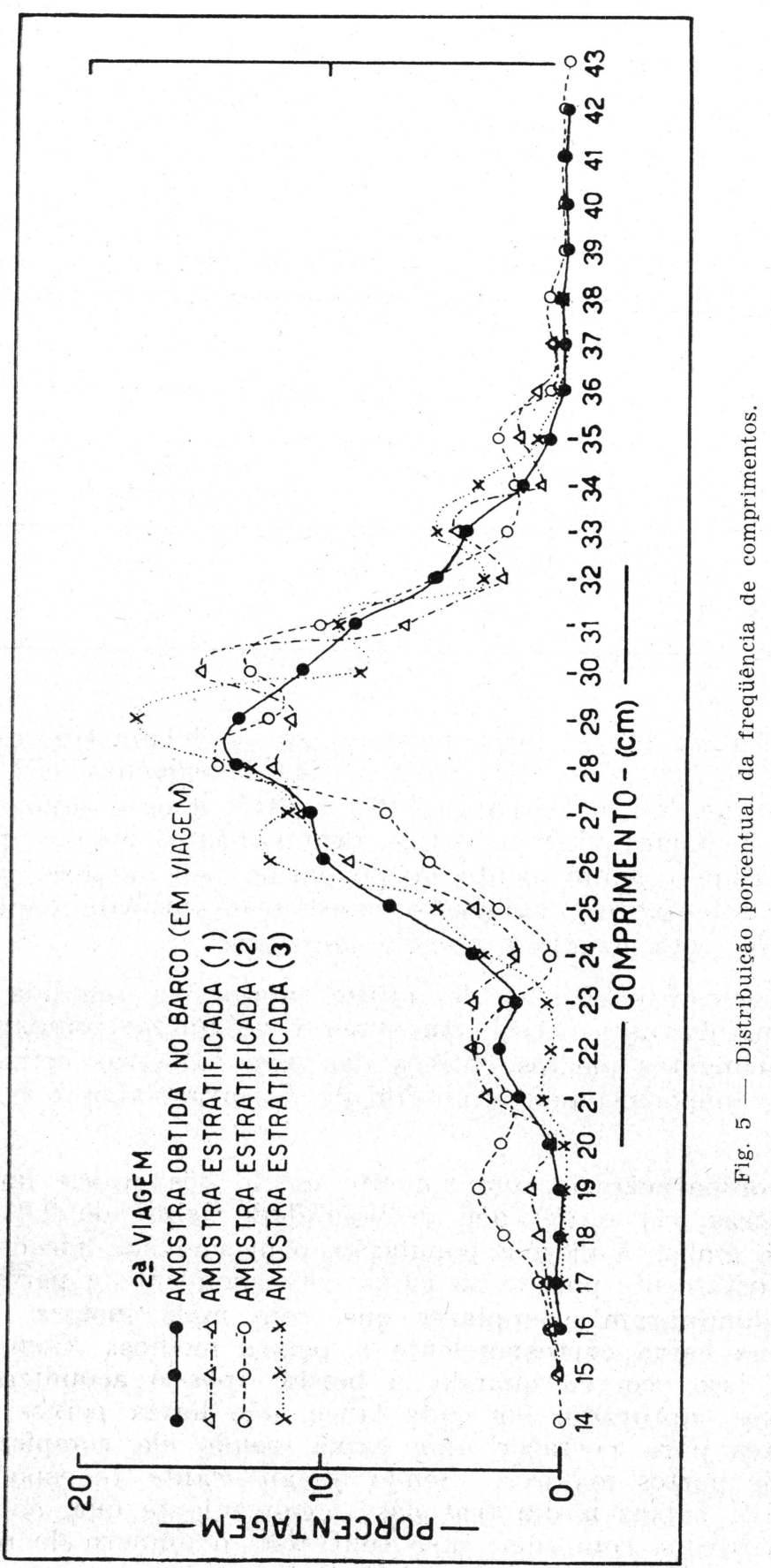


Tendo obtido o comprimento médio para as duas amostras estratificadas da primeira viagem em conjunto, bem como para as três referentes à segunda viagem (foi utilizada parte do cálculo da Tabela VIII para a obtenção dêsse comprimento médio) e comparando-os com o comprimento médio das amostras obtidas a bordo, as probabilidades de pertencerem à mesma população foram maiores do que 0,05 , ou seja, a diferença entre os comprimentos médios foi insignificante, conforme se pode notar pela tabela abaixo.

TABELA $\mathrm{X}$

\begin{tabular}{|c|c|c|}
\hline Viagem & $\begin{array}{c}\text { Comprimento médio das } \\
\text { amostras estratificadas }\end{array}$ & $\begin{array}{c}\text { Comprimento médio das } \\
\text { amostras obtidas a bordo }\end{array}$ \\
\hline $1^{3}$ & 28,89 & 28,83 \\
$2^{3}$ & 28,07 & 28,17 \\
\hline
\end{tabular}

$\mathrm{Na}$ Tabela IX as duas amostras que englobam três categorias de tamanho: grandes (G), médios (M) e pequenos (P), obtidas no meio e no fim da descarga [(2) e (3)], após o retôrno da parelha na primeira viagem, deram comprimentos médios que, comparados com o comprimento médio obtido pela análise das amostras dos sete lances englobados, mostraram probabilidades acima de 0,05 de pertencerem à mesma população.

As amostras obtidas de quinze lances, na segunda viagem, foram englobadas e o seu comprimento médio foi comparado com os comprimentos médios obtidos das três amostras estratificadas feitas no início, no meio e no fim da descarga, após o retôrno da parelha.

A comparação do comprimento médio dos quinze lances com as amostras (1) e (2) deu probabilidade acima de 0,01 de pertencerem ambas à mesma população, o mesmo não sucedendo com a (3), justamente porque na caixa correspondente a peixes pequenos predominaram exemplares que, com mais justeza, caberiam melhor na caixa correspondente a peixes médios. Como foi observado, isso ocorreu quando, a bordo, após o acondicionamento dos peixes capturados em cada lance, não havia peixes pequenos suficientes para perfazer uma caixa, sendo ela completada com peixes de portes maiores. Sendo insignificante (e esporádico) o número de caixas assim tratadas, é conveniente que, na medição, não se trabalhe com elas; caso contrário, o número de peixes pequenos desembarcados será subestimado. 
A análise da variância foi empregada para os dois casos supra (primeira e segunda viagens), tendo-se excluído a amostra (3) da segunda viagem, devido ao fato antes mencionado. Não houve variação significativa, como se pode verificar pelo exame da tabela abaixo:

TABELA XI - Análise da variância aplicada às amostras da primeira e da segunda viagem

\begin{tabular}{|c|c|c|c|c|c|c|}
\hline Viagem & $\begin{array}{l}\text { Fonte de varia- } \\
\text { cão }\end{array}$ & Variação & G.L. & Variância & $F$ & $P$ \\
\hline \multirow{3}{*}{$1^{3}$} & \multirow{3}{*}{$\begin{array}{l}\text { Dentro } \ldots \ldots \ldots \\
\text { Entre } \ldots \ldots \ldots \\
\text { Total } \ldots \ldots \ldots\end{array}$} & & & \multirow{3}{*}{$\begin{array}{r}22,72 \\
6,83\end{array}$} & \multirow[t]{3}{*}{0,30} & \multirow[t]{3}{*}{$>0,05$} \\
\hline & & 13,66 & 2 & & & \\
\hline & & $38.993,14$ & 1717 & & & \\
\hline \multirow{3}{*}{$2^{a}$} & \multirow{3}{*}{$\begin{array}{l}\text { Dentro } \ldots \ldots \ldots \\
\text { Entre } \ldots \ldots \ldots \\
\text { Total } \ldots \ldots \ldots\end{array}$} & $25.012,82$ & 1469 & \multirow{3}{*}{$\begin{array}{l}17,02 \\
24,71\end{array}$} & \multirow{3}{*}{1,45} & \multirow{3}{*}{$>0,05$} \\
\hline & & 49,43 & 2 & & & \\
\hline & & $25.062,25$ & 1471 & & & \\
\hline
\end{tabular}

4 - Rejeição de peixes no mar

Devido à ação seletiva das rêdes utilizadas pelas parelhas nipônicas sôbre o tamanho da pescada-foguete notou-se que não ocorreu rejeição da espécie de peixe sob consideração.

\section{IV - DISCUSSÃO}

Pelo que foi exposto no tópico anterior depreende-se que não há necessidade de se obter amostras de cada lance e depois englobá-las numa só amostra, embora haja variação entre elas (Tabela IV), a bordo das parelhas nipônicas, pois o comprimento médio de duas ou três amostras estratificadas (Tabela X), ou seja, medição de peixes grandes (G) contidos em duas ou três caixas, peixes médios (M) contidos em duas ou três caixas e peixes pequenos (P) contidos em duas ou três caixas, não apresenta diferença significativa quando comparado com o daquela (dados das duas viagens). Entretanto, a medição do conteúdo total de três caixas de cada categoria demandaria muito tempo; por isso foram levadas a efeito experiências (separação do conteúdo de uma caixa pela metade e medição de ambas em separado) no sentido de reduzir o número de peixes a serem medidos e, nas nossas anotações, temos: 
TABELA XII

\begin{tabular}{|c|c|c|c|c|}
\hline \multirow{2}{*}{ Categoria } & \multicolumn{2}{|c|}{ Comprimentos médios } & \multirow{2}{*}{$t$} & P \\
\cline { 2 - 3 } & 1/2 caixa & $1 / 2$ caixa & & \\
\hline P & 22,30 & 22,27 & 0,16 & $>0,05$ \\
P & 22,84 & 23,25 & 1,78 & $>0,05$ \\
P & 23,24 & 23,15 & 0,40 & $>0,05$ \\
M & 25,52 & 25,02 & 1,72 & $>0,05$ \\
M & 26,96 & 26,83 & 0,44 & $>0,05$ \\
G & 30,40 & 30,37 & 0,06 & $>0,05$ \\
G & 30,76 & 30,80 & 0,10 & $>0,05$ \\
\hline
\end{tabular}

Pela Tabela V vimos, também, que dois dos comprimentos médios gerais não apresentaram diferenças significativas, a não ser quando comparados com o terceiro. Isso levou-nos à suposição de que é necessário mais do que o conteúdo de uma caixa de cada categoria para representar a captura da parelha. Entretanto, pela Tabela XII depreende-se que basta medir metade do conteúdo de cada caixa (duas ou três de cada categoria), contando-se o restante existente nela para posterior cálculo do número total de peixes desembarcados por categoria de tamanho. Podemos concluir que uma amostragem representativa poderá ser obtida reduzindo-se o número de peixes a serem medidos de uma caixa e aumentando-se o número de caixas das quais se obterão as amostras. Dessa maneira a variância "entre" caixas será reduzida e se aproximará da variância obtida "dentro" das caixas.

Levando-se em conta que não há rejeição da espécie considerada, no mar, pelas parelhas nipônicas, supõe-se com bons fundamentos que a amostra assim obtida estará representando os peixes capturados.

Três são as parelhas nipônicas que operam entre o Cabo de Santa Marta e Rio Grande. Os comprimentos médios, bem como a distribuição dos comprimentos, são variáveis de viagem a viagem, como está provado pela análise da variância feita por categoria (Tabela VII), devido ao fator tempo. Portanto, é conveniente fazer-se amostragem do tipo mencionado, tôda vez que houver desembarque, visando-se a obtenção de boa distribuição de comprimentos durante o ano.

\section{$\mathrm{V}$ - SUMMARY}

A fishery research programme requires an accurate picture of the length distribution of the fish caught and landed. 
Each boat is considered a sampling unit. It is therefore necessary to know how to draw a sample from the fish landed in such a way as to give an accurate assessment of the length distribution of the boat's landing. This is the purpose of the present paper, which refers to the sampling of "pescada-foguete" (Macrodon ancylodon) caught by parejas of "Sociedade de Pesca Taiyo Ltda.", and landed on the fish market of Santos, State of São Paulo, Brazil.

By courtesy of that firm two voyages were made during which observations on the length distribution of the fish caught were carried out. Independently, samples were taken of the fish landed from these voyages, after landing. In this way an evaluation of the sampling techniques used on the fish market was obtained. Due to the selection of the nets used, there is no rejection of "pescada-foguete" at sea and therefore the fish measured represent a boat's catch.

\section{Methods :}

1 - Samples from the hauls were taken on board, at random, during two voyages, to find out if there is a significant difference in the length distributions between hauls on the same voyage.

2 - At the fish market three boxes of each size category: large - G, medium - $\mathrm{M}$, and small - $\mathrm{P}$, were measured: one (1) series at the beginning, the second (2) at the middle, and the third (3) at the end of the landing operation. The purpose was to see if there is a significant difference between the length distributions of each size category or if the same length distribution occurred in a given category during the entire process of landing.

3 - The grand mean, calculated according to the procedure and example given in Table VIII, for the sample quoted in item 2 above, was compared with that taken from the same vessel at sea. This shows whether the market sampling for length distribution differs significantly from that estimated from non-selected samples on the boat.

The results were as follows:

1 - In the first voyage seven samples (Table I) were obtained from seven different hauls, and the means of the samples are plotted in Figure 2; the means of the second voyage (fifteen samples) drawn at random on the following trip, are plotted in Figure 3. The $t$ test was applied for the comparison between the means and the results are shown in Tables II and III. The first three means show (Figure 2) a significant difference because at the beginning of the fishing operation several hauls were made at random to locate the shoals (Figure 1). The other four show no significant difference. The means of the second trip do not show, in general, a significant difference, probably due to the fact that the fishing was done at the same distance from the coast during the whole trip.

For estimation of the variability of all samples together, analysis of variance was used (Table IV). The value of $F$ is high in the first voyage, but not very high in the second.

2 - The difference between the mean length of the same size category taken at the beginning (1), at the middle (2), and at the end (3) of the landing was not highly significant (Tables $\mathrm{V}$ and VI).

3 - Table IX shows the comparison between the grand mean (see how it was computed in Table VIII) and the mean resulting from the gathering of samples obtained aboard the ship, in the first and in the second voyage. Those concerning the first trip do not show a significant difference; the 
same is true of two [(1) and (2)] from the second trip. The other (3) shows a significant difference because at the end of the landing some fish of bigger size than those normally considered as small were placed in the box of small fish measured. A percentage length frequency distribution of the raised market data and the boat samples (Figs. 4 and 5) shows practically no difference. Also, there is no significant difference between the samples obtained on board and those obtained on the fish market (grand mean for the two stratified samples of the first voyage, and for the three samples of the second one), as shown in Table $X$, i.e., the mean of two stratified samples taken at the fish market at the return from the first trip, when compared with the one obtained aboard, showed no significant difference. The same is evident with the three stratified samples obtained at the return from the second trip.

The size distribution within a category is not the same for every landing (Tables VII and VIII). Therefore, from every landing a stratified sample must be drawn. Table $\mathrm{V}$ shows that two general means present no significant difference, but this is not so when compared with the third one. This suggests that more than one box is necessary to represent the catch of a pareja belonging to "Sociedade de Pesca Taiyo Ltda.". Table XII shows, however, that the measurements of half a box of $25 \mathrm{~kg}$, and the counting of the other half (to raise the total number of fish landed at each size category) are sufficient enough to represent the box. The most important conclusion is that a better representative sampling can be achieved by reducing the number of fish measured from each box, and increasing the number of boxes measured for fish. Thus the variance between boxes will be reduced and it will fall nearer to the variance within each box.

\section{VI - AGRADECIMENTOS}

$\mathrm{O}$ autor agradece a orientação dada por Mr. Ian Dennis Richardson, técnico da FAO, e as sugestões apresentadas pelo Eng. Antônio Garcia Occhipinti, meteorologista do Instituto Oceanográfico da USP. Os agradecimentos são extensivos à Sociedade de Pesca Taiyo Ltda., proprietária do barco "Akashi Maru 33", no qual viajou o autor, e em especial ao Capitão dêsse barco, Sr. Shigeo Kobayashi, pela cordial acolhida a bordo e informações prestadas sôbre técnicas de pesca. São também credores da gratidão do autor todos os membros do Grupo de Pesquisas sôbre a Pesca Marítima que colaboraram na execução dêste trabalho.

\section{VII - BIBLIOGRAFIA}

Croxton, F. E. \& Cowden, D. J.

1952. Estatística geral e aplicada. Rio de Janeiro, Inst. Bras. Geog. Est. xxiii +1096 p., 257 graf.

Pope, J. A.

1956. An outline of sampling techniques. Rapp. Proc. — Verb. Réun., vol. 140, Part I, p. 11-20. 